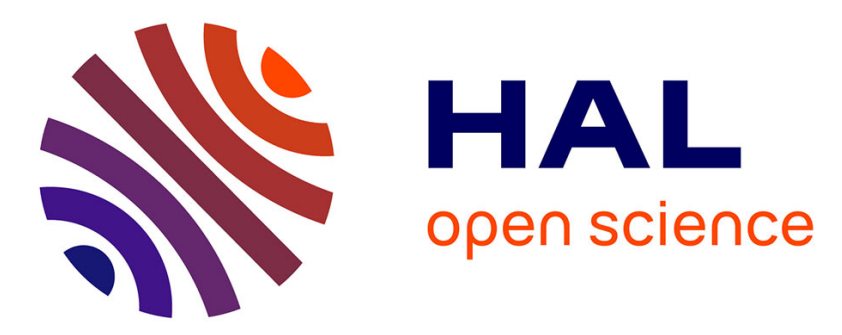

\title{
An experimental technique for the measurement of temperature fields for the orthogonal cutting in high speed machining
}

Guy Sutter, Laurent Faure, Alain Molinari, Nicolas Ranc, Vincent Pina

\section{- To cite this version:}

Guy Sutter, Laurent Faure, Alain Molinari, Nicolas Ranc, Vincent Pina. An experimental technique for the measurement of temperature fields for the orthogonal cutting in high speed machining. International Journal of Machine Tools and Manufacture, 2003, 43, pp.671-678. 10.1016/S08906955(03)00037-3 . hal-00283393

\section{HAL Id: hal-00283393 https://hal.science/hal-00283393}

Submitted on 16 Mar 2018

HAL is a multi-disciplinary open access archive for the deposit and dissemination of scientific research documents, whether they are published or not. The documents may come from teaching and research institutions in France or abroad, or from public or private research centers.
L'archive ouverte pluridisciplinaire HAL, est destinée au dépôt et à la diffusion de documents scientifiques de niveau recherche, publiés ou non, émanant des établissements d'enseignement et de recherche français ou étrangers, des laboratoires publics ou privés. 


\title{
An experimental technique for the measurement of temperature fields for the orthogonal cutting in high speed machining
}

\author{
G. Sutter ${ }^{\mathrm{a}, *}$, L. Faure ${ }^{\mathrm{a}}$, A. Molinari ${ }^{\mathrm{a}}$, N. Ranc ${ }^{\mathrm{b}}$, V. Pina ${ }^{\mathrm{b}}$ \\ ${ }^{a}$ L.P.M.M., U.M.R. C.N.R.S. n7554, I.S.G.M.P., Université de Metz Ile du Saulcy, 57045 Metz Cedex 1, France \\ ${ }^{\mathrm{b}}$ L.E.E.E., E.A.387, Université de Paris X Nanterre 1, chemin Desvallières, 92410 Ville d'Avray, France
}

Cutting temperature and heat generated at the tool-chip interface during high speed machining operations have been recognized as major factors that influence tool performance and workpiece geometry or properties. This paper presents an experimental setup able to determine the temperature field in the cutting zone, during an orthogonal machining operation with $42 \mathrm{CrMo} 4$ steel. The machining was performed with a gas gun, using standard carbide tools TiCN coated and for cutting speeds up to $50 \mathrm{~ms}^{-1}$. The technique of temperature measurement was developed on the principle of pyrometry in the visible spectral range by using an intensified CCD camera with very short exposure time and interference filter at $0.8 \mu \mathrm{m}$. Temperature gradients were obtained in an area close to the cutting edge of the tool, along the secondary shear zone. Effects of the cutting speed and the chip thickness on the temperature profile in the chip were determined. Maximum chip temperature of about $825^{\circ} \mathrm{C}$ was found, for cutting speed close to $20 \mathrm{~ms}^{-1}$, located at a distance of $300 \mu \mathrm{m}$ of the tool tip. It was established that this experimental arrangement is quite efficient and can provide fundamental data on the temperature field in materials during orthogonal high speed machining.

\section{Introduction}

Due to their excellent physical properties, which include a low thermal conductivity or a high hardness, materials such as titanium alloys or nickel-based alloys are used in many applications. Because of these characteristics, their machining leads to difficulties even at low cutting speeds or low feed rates. For these materials, high speed machining described by Shaw [1], Trent [2] or Schulz [3], seems to be an excellent solution to increase productivity and to reduce machining cost. However, removal of more material in a shorter time increases the heat generation in the cutting zone. Practically all the energy expended in metal cutting is transformed into heat near the cutting edge of the tool. Heat concentration in the area of contact can affect the dimensional accuracy of the workpiece, influence the performance of the tools or lead to important tool damages and

* Corresponding author. Tel.: +33-3-87-31-53-67; fax: +33-3-8731-53-66.

E-mail address: sutter@lpmm.univ-metz.fr (G. Sutter). breakage. For these reasons it is important to examine in detail the different factors which influence the temperature distribution on the tool rake surface. It has been established that the mean tool temperature on the rake face is proportional to $\mu \sqrt{V f /(K \rho C)}[1]$, where $\mu$ is the specific cutting energy; $V$ is the cutting speed; $f$ is the feed rate; $K, \rho$ and $C$ are the thermal conductivity, the density and the specific heat of the workpiece. The relation suggests that a small value of the product $K \rho C$ causes the temperature to rise, even at a relatively low cutting speed and feed rate.

Attempts have been made to determine the temperature at the tool chip interface by direct measurement. Many investigators have developed several techniques for assessing these cutting temperatures during high speed machining processes. Let us quote for example embedded thermocouple, tool-work thermocouples, change in hardness, thermal color techniques, powders of constant melting points, infrared photography, etc. Several reviews of experimental techniques for measurement methods are proposed by Barrow [4], and more recently by Komanduri et al. [5] or Bacci Da Silva et al. [6]. Precise measurements of these cutting temperatures are a fundamental point in machinability research. 
The aim of this work is to present an experimental setup able to establish the temperature field in the cutting zone during orthogonal cutting. The technique of temperature measurement was developed on the principle of pyrometry in the visible spectral range by using an intensified CCD camera with very short exposure time and interference filter centered at $0.8 \mu \mathrm{m}$. This equipment is used with the gas gun developed by Sutter et al. [7] able to simulate orthogonal machining up to cutting speeds of $80 \mathrm{~ms}^{-1}$. Effects of cutting conditions (feed, cutting speed) on the temperature distribution are analyzed.

\section{Methods used to estimate temperature in high speed machining}

\subsection{Thermocouple technique}

The most extensively used methods are based on two different thermocouple techniques with respectively embedded thermocouple and tool-work thermocouple, so-called dynamic thermocouple. The principle of the temperature measurement by a thermocouple is that when two different metals are connected together, and if these parts called hot and cold junctions are maintained at two different temperatures, an electromotive force (emf) is produced across these two junctions. The emf generated is a function of the materials used for the thermocouple as well as the temperatures of the junctions. In machining applications, a thermo electric emf is generated between the tool and the workpiece. A standard thermocouple assembly embedded into a cutting tool or workpiece is known as an implanted inserted or remote thermocouple. Numerous authors studied the evolution of temperature in manufacturing using embedded thermocouples. Kitigawa et al. [8] used this technique to investigate the influence of temperature on the tool wear, during high speed turning of Inconel 718 and high speed milling of Ta6V alloys. Their thermocouple consisted of a tungsten wire, which was embedded in the tool. An edge of the wire was exposed on the rake face by grinding. The chip sliding on this rake face breaks the insulation to create a hot junction between the wire and the exposed site on the tool. They reported temperatures close to $1200{ }^{\circ} \mathrm{C}$ (close to the melting temperature of this alloy) at $150 \mathrm{~m} \cdot \mathrm{min}^{-1}$, for a ceramicInconel 718 tool-material pair, and temperatures of about $1100{ }^{\circ} \mathrm{C}$ for a carbide-Ta6V tool-material pair at 500 m. $\mathrm{min}^{-1}$. El-Wardany et al. [9] employed another technique, with a K-standard thermocouple, in which the hot junction was clamped in a recess which was ground off the rake face of the tool to locate the thermocouple as close as possible to the cutting edge. They carried out several attempts to evaluate the influence of cutting process parameters on the cutting temperature with two dif- ferent workpiece materials, AISI 1552 and Inconel 718. The results obtained for the Inconel 718 initially showed a decrease of the cutting edge temperature when the cutting speed increased, but with a further increase in the cutting speed the temperature also increased. For the authors, the initial decrease is explained by the dependence of the thermal diffusivity of the Inconel 718 with the temperature, and for higher speeds, a pressure welding of workpiece material between the tool and the workpiece affects the thermal conductivity of the cutting edge leading to an increase of the temperature. Grzesik [10] analyzed the influence of several tool coats on the interfacial temperatures with both flat-faced and grooved inserts on AISI 1045 and AISI 304 steels. He put in evidence the important role of friction at the rake face on heat generation, for cutting speeds close to $200 \mathrm{~m} \cdot \mathrm{min}^{-1}$ in turning. O'Sullivan and Cotterell [11] measured the temperatures in turning using two thermocouples in the workpiece (Aluminum 6082-T6). They indicated that an increase in cutting speed resulted in a decrease of the temperature in machined surface. They attributed this reduction in temperature to the higher metal removal rate, which resulted in more heat being carried away by the chip and thus less heat being conducted into the workpiece. Ay and Yang [12] used a technique with Kthermocouples to analyze temperature variations in carbide inserts in cutting various materials such as copper, cast iron, aluminum 6061 and AISI 1045 steel. They observed oscillations in temperature near the cutting edge, which were more marked for ductile materials and less in the hard-machining materials. These observations were attributed to the chip formation, which raises the local temperature upon its contact with the work material. Still let us quote the works of Byrne [13] or Usui et al. [14].

When embedded thermocouples are employed in tools, several holes are made and the thermocouples are inserted in different locations in the interior of the tool with some of them as close to the surface as possible. These thermocouples are simple to build, have a low cost price and are simple to put in operation. However, a high number of drillings are required to determined the distribution of the temperature at the tool chip interface with good accuracy. These numerous holes can alter heat conduction into the tool as well as limit the strength of the tool. As a consequence, generally only one hole is drilled in each tool and to cover the entire section of the cutting zone, several tools are used with holes located in different zones. This technique has some limitations: (1) the placement of the thermocouple can interfere with the heat flow, (2) it is a tedious procedure to estimate with precision the gradient of temperature, (3) there are difficulties in drilling holes in difficult-tomachine materials such as ceramic, polycrystalline diamond, cemented carbide tools, (4) a transient response becoming more important with an increasing size of the 
sensor. These restrictions allowed the development of an additional method to determine temperatures with thermocouples called the tool-work (tool-chip) thermocouple or dynamic thermocouple. This technique was used by Alvelid [15], Stephenson [16], Lezanski et al. [17] or Groover et al. [18]. With this method, the entire tool is used as a part of the thermocouple and the workpiece as the other part. The cutting zone forms the hot junction while a cold part of the tool and the workpiece forms the cold junction. The thermo electric emf generated between the tool workpiece interface is then measured. The tool support and the workpiece need to be electrically insulated from the machine tool. This technique is relatively simple to use but it has some drawbacks. The tool-chip thermocouple gives only a mean value of the temperature at the tool chip interface, not the maximum, while a temperature gradient exists. It is necessary to have an accurate calibration of the tool and the workpiece material as a thermocouple pair. Each tool-work combination requires a separate calibration. Results can be incorrect if a built up edge is formed. A cutting fluid cannot be used.

\subsection{Radiation techniques}

Another method employed to investigate the cutting temperature during chip formation in machining is the non-contact thermographic technique [19]. With the thermographic technique the radiations from the tool, the workpiece and the chip are measured to establish the temperature field on the outside surfaces of these regions. The first use of this technique for determining the temperature distribution at the surface of the tool and workpiece was reported by Schwerd [20] who developed a radiation pyrometer where the radiations were beamed on a thermocouple with an optical condenser. Lin et al. [21] presented an experimental measurement using infrared pyrometer with fiber optic. The sensor is put at several locations on the rake face, near the cutting edge to determine the tool chip temperature and the total heat dissipated for tungsten carbide and ceramic inserts and for cutting speeds close to $600 \mathrm{~m} \cdot \mathrm{min}^{-1}$. It was found that the thermal conductivity of the tool material has little effect of the cutting interface temperature. A development of this technique was infrared photography, first proposed by Boothroyd [22]. More recently, Young [23] used a high sensitivity infrared detector to determine the temperature of the chip back section during orthogonal cutting of AISI 1045 steel. He showed a rapid increase of the temperature corresponding to a sudden breakdown of the sharp cutting edge. Da Silva et al. [24] presented an application to measure the temperature of the machined surface of AISI 1040 steel, just below the cutting edge. By measuring the temperature at three different locations, the results were used to extrapolate to the cutting edge. Dewes [25] employed an infrared camera to acquire chip temperature when machining hardened mould/die steel AISI H13 in high speed machining and compared results with measurements carried out with a K-thermocouple wire. In their experiments, the infrared technique indicated lower temperatures than the thermocouple method. They explained these results by the drawbacks of the infrared technique; due to edge effects, the measured temperatures are lower than those actually occurring in the bulk of the material. The other main difficulty with radiation techniques is that they are generally limited to accessible surfaces.

Numerous other techniques have been developed to investigate temperature distribution at the tool-chip interface. Wright et al. [26] proposed a metallographic method to determine temperature gradients in cutting tools; Yeo et al. [27] estimated thermal effect on chip surface by a chip color approach. However, these methods are laborious and difficult to use.

\section{Experimental device}

\subsection{Mechanical part}

An original device is used to measure the temperature during the cutting process. This process perfectly reproduces the conditions of orthogonal cutting [7-28] and allows a good accessibility for photographic recordings. Moreover, its high rigidity drastically reduces the parasite vibrations observed in conventional machines. Tools are fixed and the specimen moves in a rectilinear movement, thus allowing a perfect recording.

This cutting device, Fig. 1, consists of a tool holding fixture fixed to a tube and an air gun animating a projectile. The sample to be manufactured is fixed on the projectile propelled by the relaxation of compressed air and driven in a launch tube, which ensures a precise guiding of the projectile. The tool holding fixture fixed at the entry of the second tube (Hopkinson tube) supports two tools symmetrically positioned. At the end of this second tube, a shock absorber stops the projectile and the specimen. The whole process is locked into a box to get back chips and avoid outside brilliance. A wide range of projectile speed (equal to the cutting speed) is possible with this process $\left(10-100 \mathrm{~ms}^{-1}\right)$. Speed and acceleration are measured by a set of photo-diodes and a time counter.

The depth of cut is controlled by the difference of the initial width of the specimen with the tool distance and is checked by the precise measurement of the specimens before and after each test.

All the tests were carried out using carbide tools, with a new tool being used for each shot. The tools were square shaped, without a chip-breaker. The rake angle was $0^{\circ}$.

The measurements of the cutting forces are achieved using strain gages located on the tool holding fixture. 


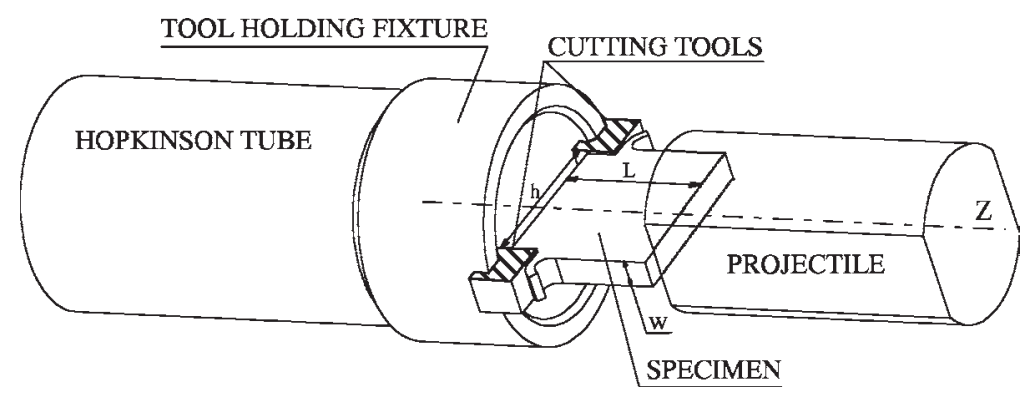

Fig. 1. Detail of the tool holding fixture and the specimen.

\subsection{Pyrometric measurements}

The pyrometry technique developed in this study has many advantages compared to the conventional systems. First it is a nonintrusive technique which does not disturb the measurement. Secondly, the response time can be very short (between 50 nanoseconds and 20 milliseconds), and enables us to study very fast phenomena. Thirdly, the space resolution, which is only limited by the wavelength of the optical radiation, can be very high. However, this measurement technique presents difficulties related especially to uncertainty on the emissivity of the specimen surface. The emissivity can depend on the surface temperature [29], roughness [30] of the surface and possible phase transitions [31].

The radiation emitted by a sample at the real temperature $\mathrm{T}_{r}$ is related to the radiance temperature $\mathrm{T}_{\lambda}$ by the Planck law.

$\mathrm{L}_{\lambda}=\frac{\mathrm{C}_{1} \lambda^{-5}}{\exp \left(\frac{\mathrm{C}_{2}}{\lambda \mathrm{T}_{\lambda}}\right)-1}$

with: $\mathrm{C}_{1}=1,191062 \cdot 10^{8} \mathrm{~W} \cdot \mu \mathrm{m}^{4} \mathrm{~m}^{-2} \cdot \mathrm{sr}^{-1}, \mathrm{C}_{2}=14388$ $\mu \mathrm{m} . \mathrm{K}, \lambda$ the wavelength in $\mu \mathrm{m}, \mathrm{L}_{\lambda}$ : the monochromatic radiance expressed in $\mathrm{W} / \mathrm{m}^{-2} \cdot \mu \mathrm{m}^{-1} \cdot \mathrm{sr}^{-1}$.

If the Wien approximation is verified $\left(\exp \left(\frac{\mathrm{C}_{2}}{\lambda \mathrm{T}_{\lambda}}\right) \gg 1\right)$, the following relationship can be written between the real temperature and the radiance temperature in the case of monochromatic pyrometry:

$\frac{1}{\mathrm{~T}_{\mathrm{r}}}=\frac{1}{\mathrm{~T}_{\lambda}}+\frac{\lambda}{\mathrm{C}_{2}} \ln \left(\varepsilon_{\lambda}\right)$

where $\epsilon_{\lambda}$ is the emissivity of the surface material at the monochromatic wavelength $\lambda$. We can notice that the real temperature is always higher than the radiance temperature. The relative error on the temperature induced by the emissivity factor can be quantified as:

$\frac{\Delta \mathrm{T}}{\mathrm{T}_{\mathrm{r}}}=-\mathrm{T}_{\lambda} \frac{\lambda}{\mathrm{C}_{2}} \ln \left(\varepsilon_{\lambda}\right)$

This relative error decreases when the wavelength of the optical radiation is getting smaller. Therefore, the measurement wavelength should be taken the smallest as possible. The curves, Fig. 2, show the relative error versus the radiance temperature for different wavelength and emissivity values. $2.5 \mu \mathrm{m}$ corresponds to the wavelength of maximum radiative emission for a temperature of approximately $900{ }^{\circ} \mathrm{C}$ (this value is given by the Wien law). $0.8 \mu \mathrm{m}$ is chosen for our measurements. The maximum errors are about $10 \%$ at $0.8 \mu \mathrm{m}$ and $40 \%$ at $2.5 \mu \mathrm{m}$ for a temperature around $1000^{\circ} \mathrm{K}$. In the following paper we will consider that the difference between the real temperature and the luminance temperature is negligible.

The optical device consists of an intensified CCD camera and an interference filter centered at $0.8 \mu \mathrm{m}$ with a $0.01 \mu \mathrm{m}$ bandwidth. A glass lens with a focal length of $100 \mathrm{~mm}$ collects the heat flux. The optical alignment with the specimen is carrying out using a HeNe laser. The experimental configuration is represented in Fig. 3.

The calibration of the optical device is performed using a reference source like a blackbody. The curve, Fig. 4, shows the level of the intensified camera versus the blackbody temperature. The opening duration of the camera is $64 \mu \mathrm{s}$. The average of the background noise is around 20 camera levels. Table 1 represents the measurement error versus the temperature.

\section{Presentation of the results}

Experiments have been performed on a medium carbon steel (42CrMo4) with chemical composition specified in Table 2.

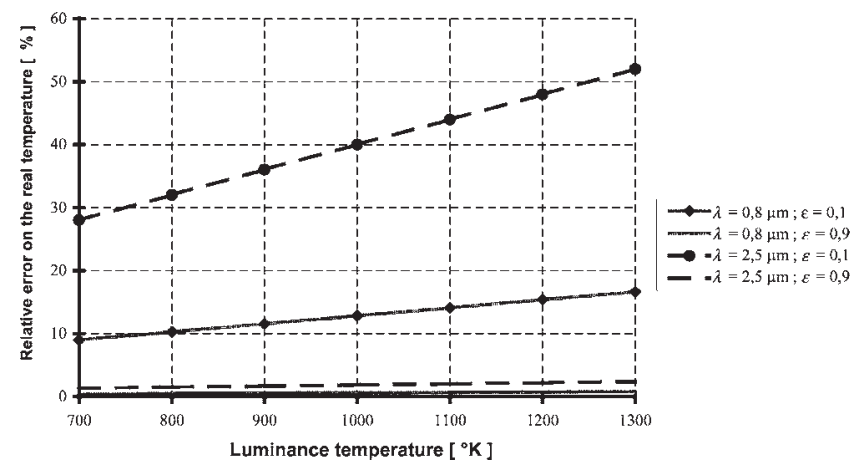

Fig. 2. Relative error on temperature measurement for different wavelength and emissivity values. 


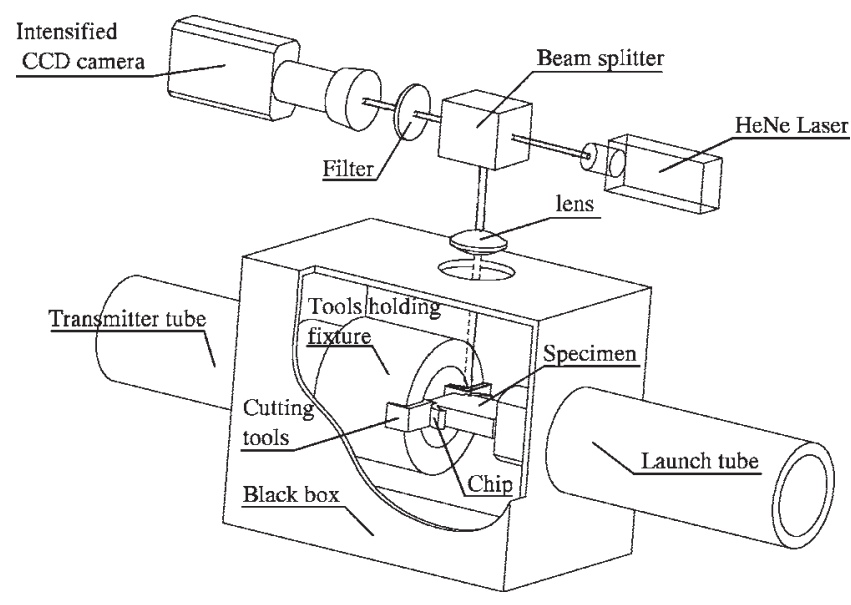

Fig. 3. Scheme of the experimental apparatus.

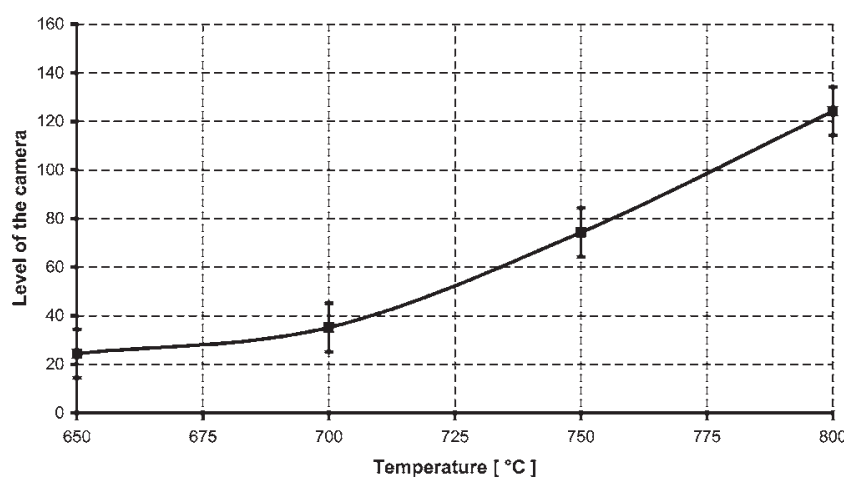

Fig. 4. Calibration curve of the intensified camera vs the blackbody temperature.

\subsection{Spatial distribution of the temperature}

Fig. 5 shows the location of the analysis area and a thermography for a test at a cutting speed $V=20 \mathrm{~ms}^{-1}$, for an undeformed chip thickness $\mathrm{t}_{1}=0.5 \mathrm{~mm}$ and a rake angle $\alpha=0^{\circ}$. This recording allows to localize the tool

Table 1

Temperature measurement error

\begin{tabular}{ll}
\hline Temperature & Measurement error \\
\hline $700{ }^{\circ} \mathrm{C}$ & $45^{\circ} \mathrm{C}$ \\
$750{ }^{\circ} \mathrm{C}$ & $23^{\circ} \mathrm{C}$ \\
$800{ }^{\circ} \mathrm{C}$ & $16^{\circ} \mathrm{C}$ \\
\hline
\end{tabular}

tip position. Indeed, on this picture the machined surface can be visualized from the residual temperature due to the cutting process. The clearance angle of the cutting tool is outline by a white line to fully understand the picture. For this recorder the release of the camera is carried out with a delay of $50 \mu$ s after initiation of cutting and the opening duration is $64 \mu \mathrm{s}$.

Fig. 6 presents the cutting force signal measured on the tool holding fixture with a set of strain gages. The amplitude of this signal is proportional to the cutting force intensity. On Fig. 6 we have also shown the opening signal of the camera.

Different tests with two release times were realized to analyse the time dependence of the heating phenomenon. Table 3 presents the values of the experimental measurements of the average (on space and time) temperature at the point $\mathrm{C}$ (cf. Fig. 8). Spatial averaging corresponds to a $10 \mu \mathrm{m} \times 10 \mu \mathrm{m}$ (7 pixels $\times 7$ pixels) area, time averaging is made over the camera opening duration.

Note that the thermal process can be considered as quasi-stationary in view of the weak variation of the average temperature when the delay time is increased from $50-100 \mu$ s. This observation was already made by Lim et al. [32].

The thermography of Fig. 5 obtained for the cutting speed $V=20 \mathrm{~ms}^{-1}$, shows a maximum of the temperature rising to $825{ }^{\circ} \mathrm{C}$ located near the tool-chip interface at a distance of $50 \mu \mathrm{m}$ and at a distance of 300-350 $\mu \mathrm{m}$ from the tool tip. The curves Fig. 7a and $b$ represent the temperature evolution according to a perpendicular line (line 1) and parallel line (line 2) to the tool-chip interface and passing by the point of maximum temperature (see Fig. 5). The high temperature zone that appears along the length of the cutting tool face indicates the predominance of the friction component of heating with regard to the intense shearing in the primary band. The camera dynamics does not allow us to measure a temperature variation higher than $200{ }^{\circ} \mathrm{C}$. Also the calibration of the maximum recorded temperature was chosen according to the maximum temperature in the chip. This explains that the lower temperature, which can be measured, is around $650{ }^{\circ} \mathrm{C}$.

The movement to the left of $10 \mu \mathrm{m}$ against the tool interface of the temperature profile becomes from the temperature diffusion in the tool (cf. Appendix).

Table 2

Chemical composition of the $42 \mathrm{CrMo} 4$ steel

\begin{tabular}{lllllllllll}
\hline Elements & $\mathrm{C}$ & $\mathrm{Si}$ & $\mathrm{Mn}$ & $\mathrm{S}$ & $\mathrm{P}$ & $\mathrm{Ni}$ & $\mathrm{Cr}$ & $\mathrm{Mo}$ & $\mathrm{Cu}$ & $\mathrm{Al}$ \\
\hline $10^{-3}$ & 465 & 224 & 942 & 17 & 15 & 171 & 1070 & 265 & 245 & 22 \\
\hline
\end{tabular}




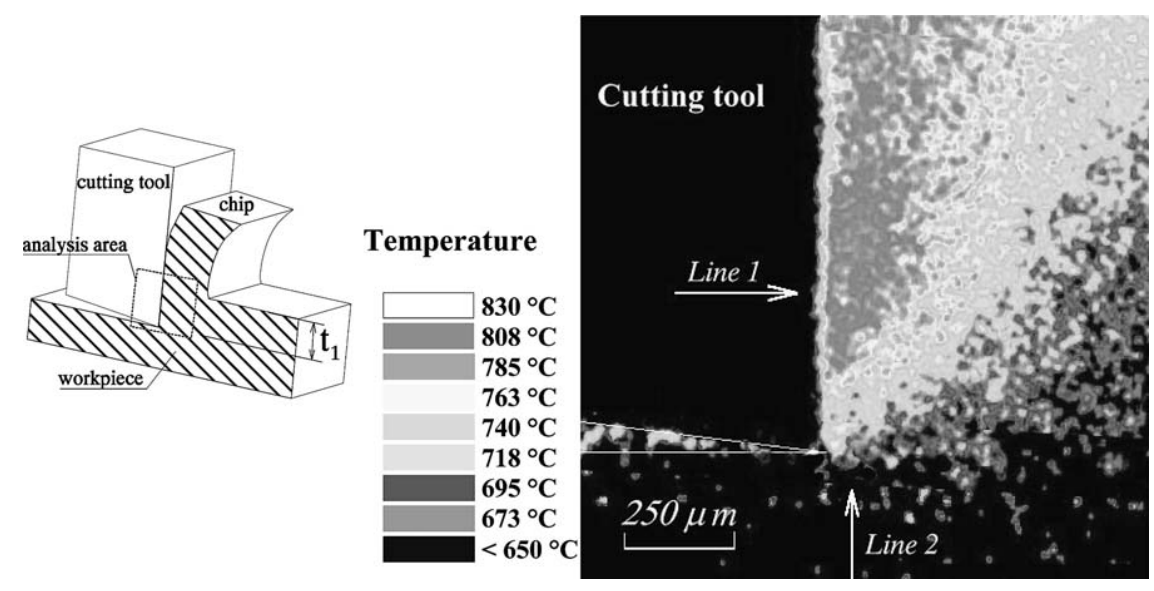

Fig. 5. Spatial distribution of the temperature. Undeformed chip thickness $t_{1}=0.5 \mathrm{~mm}$, rake angle $\alpha=0^{\circ}$, time exposure $=64 \mu \mathrm{s}$, cutting speed $V=20 \mathrm{~m} / \mathrm{s}$.

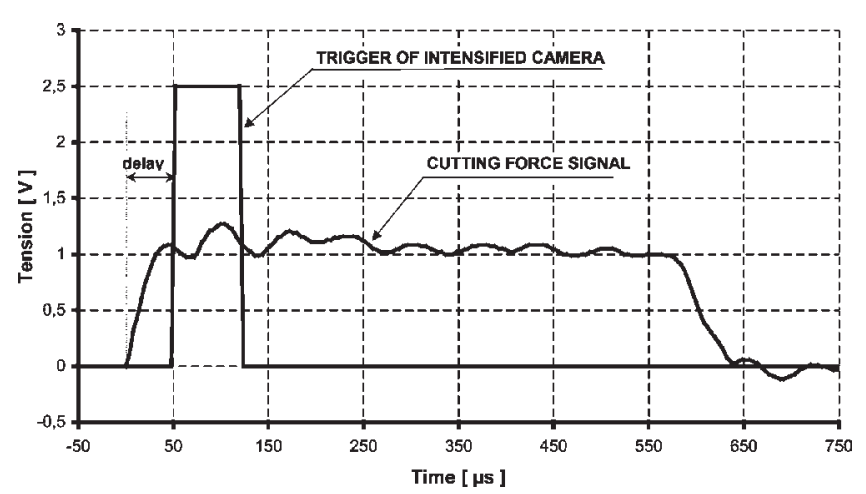

Fig. 6. Cutting force and trigger of intensified camera recording.

Table 3

Temperature measurement for different delay-times

\begin{tabular}{lll}
\hline Test number & Delay-time & Temperature measurement \\
\hline R1 & $50 \mu \mathrm{s}$ & $784^{\circ} \mathrm{C}$ \\
R3 & $100 \mu \mathrm{s}$ & $765^{\circ} \mathrm{C}$ \\
\hline
\end{tabular}

\subsection{Effect of the cutting speed on the temperature}

Temperature measurements were performed for orthogonal cutting tests in the velocities range 20 $\mathrm{ms}^{-1}<V<45 \mathrm{~ms}^{-1}$. The undeformed chip thickness is $\mathrm{t}_{1}=0.5 \mathrm{~mm}$ and the opening duration is $64 \mu \mathrm{s}$. The average temperature was determined on a $10 \mu \mathrm{m} \times 10$ $\mu \mathrm{m}$ area located at a distance of $300 \mu \mathrm{m}$ from the tool tip and at a distance of $20 \mu \mathrm{m}$ and $70 \mu \mathrm{m}$ from the tool interface (points $\mathrm{C}$ and $\mathrm{D}$ on Fig. 8). Fig. 8 shows that the temperature at these two points increases with an increase of the cutting speed. The dependence of the temperature on the cutting speed is more pronounced for an increase from $20-30 \mathrm{~ms}^{-1}$. For cutting speeds larger than $40 \mathrm{~ms}^{-1}$, the temperature seems to stabilise at 840 ${ }^{\circ} \mathrm{C}$ at the two points $\mathrm{C}$ and $\mathrm{D}$. This cutting speed is close (a)

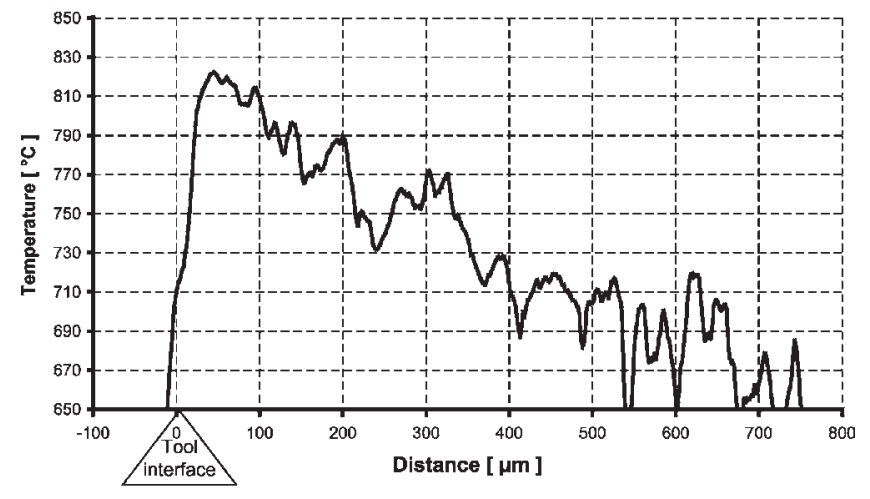

(b)

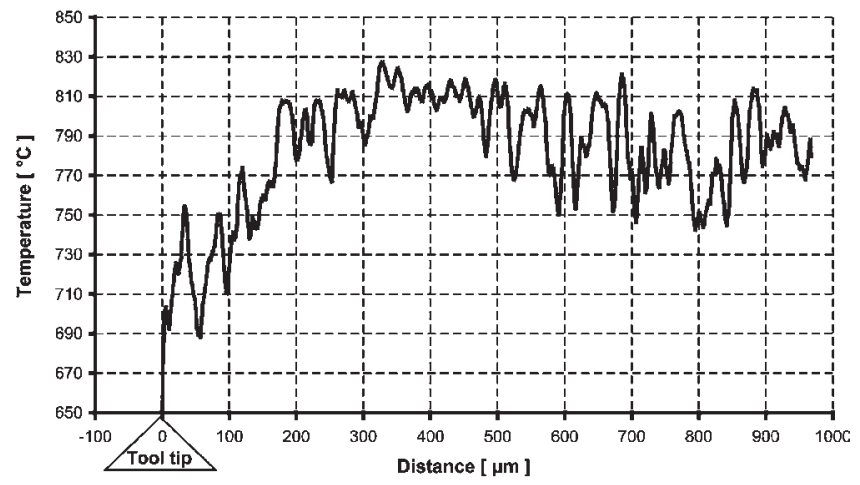

Fig. 7. (a) Perpendicular temperature profile on line 1 of Fig. $5 t_{1}$ $=0.5 \mathrm{~mm}, \alpha=0^{\circ}, V=20 \mathrm{~ms}^{-1}$. (b) Temperature profile on line 2 parallel to the tool interface at the distance of $50 \mu \mathrm{m}, t_{1}=0.5 \mathrm{~mm}$, $\alpha=0^{\circ}, V=20 \mathrm{~ms}^{-1}$.

to the value corresponding to the minimum of the cutting force already observed [7-28]. The decrease of the cutting force when the cutting speed is increased can be explained by the decay of the mean friction coefficient at the tool rake face. This friction coefficient seems to vary as a decreasing function of the interface temperature. The minimum of the cutting force is obtained at a 


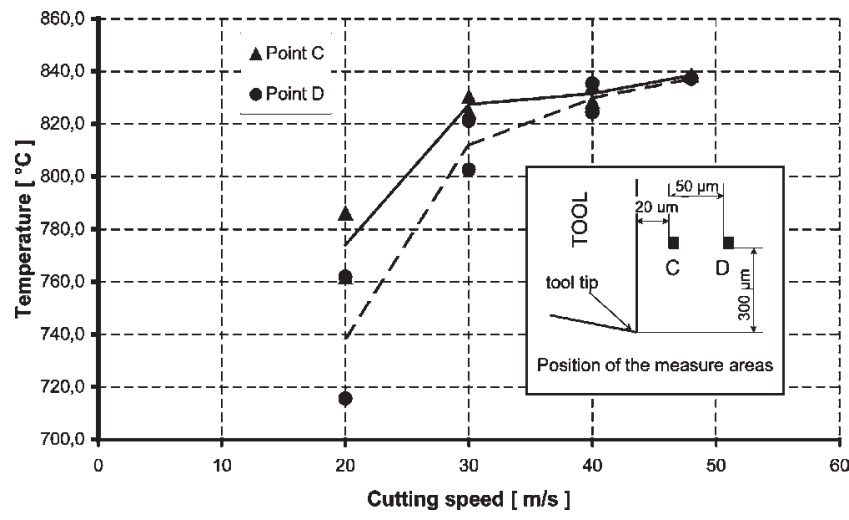

Fig. 8. Effect of the cutting speed on the temperature at points $C$ and $D$ in the chip $t_{1}=0.5 \mathrm{~mm}, \alpha=0^{\circ}$.

cutting speed of about $40 \mathrm{~ms}^{-1}$ for which the temperature saturates at the value $850{ }^{\circ} \mathrm{C}$. For velocities larger than $40 \mathrm{~ms}^{-1}$, the cutting force is observed to increase [7-28]. This is due to the effects of inertia forces, which become significant at high cutting speeds.

\subsection{Effect of the chip thickness on the temperature}

For a cutting speed fixed to a value of $40 \mathrm{~ms}^{-1}$, the temperature distribution is measured at the tool chip interface and at a distance $\mathrm{d}$ given by $d=d^{\circ} . t / t^{\circ}$ of the tool tip. We fix the constant $d^{\circ}=200 \mu \mathrm{m}$ and $t^{\circ}=$ $400 \mu$ s. The evolution of the temperature according to the chip thickness is presented Fig. 9.

An increase in the depth of cut results in an increase of the cutting temperature in the chip and soon converges to a steady-state value about of $840{ }^{\circ} \mathrm{C}$.

\section{Conclusion}

The accessibility and the stability of the cutting device using a pneumatic air gun to reproduce orthogonal cutting permits us to visualise easily the tool-chip interface. The technique of pyrometry in the visible spectral range

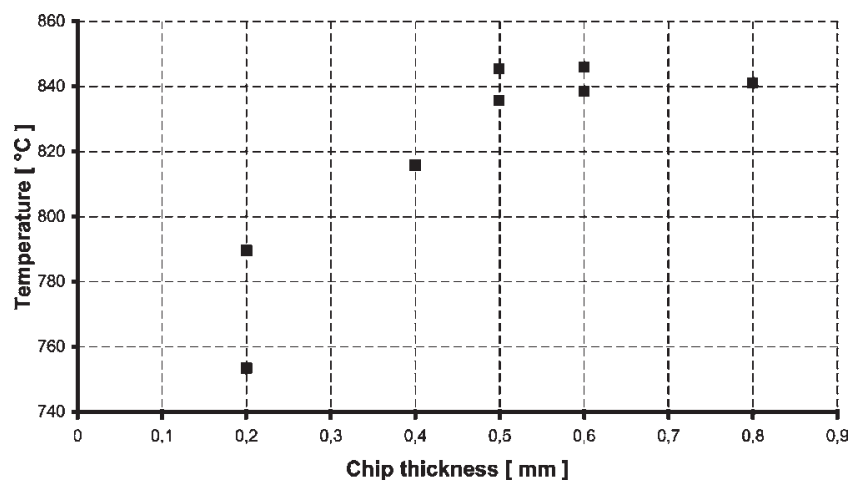

Fig. 9. Effect of the undeformed chip thickness on the temperature $\alpha=0^{\circ}, V=40 \mathrm{~ms}^{-1}$. by using an intensified CCD camera allows us to determine the temperature at the tool-chip interface. It was established that this experimental arrangement is quite efficient and can provide fundamental data on the temperature field in materials during orthogonal high speed machining.

The results allow us to observe the following points: A hot spot exit in the distribution of the temperature into the chip during the cutting process. For a cutting speed of $20 \mathrm{~ms}^{-1}$ this hot spot is located near the tool-chip interface at a distance of $300-350 \mu \mathrm{m}$ of the tool tip. This value corresponds to about the two-thirds of the depth of cut. The reaching temperature is around $825^{\circ} \mathrm{C}$.The temperature in the chip increases with increasing of the cutting speed. The dependence of the temperature on the cutting speed is more pronounced for an increase from $20-30 \mathrm{~ms}^{-1}$. For cutting speeds larger than $40 \mathrm{~ms}^{-1}$, the temperature seems to stabilise. A similar tendency is observed with the increasing in the depth of cut and for a cutting speed fixed to $40 \mathrm{~m} / \mathrm{s}$. For a undeformed chip thickness larger than $0.5 \mathrm{~mm}$ the temperature in the chip is nearing a saturated value about of $840{ }^{\circ} \mathrm{C}$ during the process.

\section{Appendix A}

This part determines the theoretical temperature field in the tool. At the tool-chip interface the temperature is fixed at $820{ }^{\circ} \mathrm{C}$ during $50 \mu$ s or $100 \mu \mathrm{s}(\mathrm{T}(x=0, t)=$ $T_{i}=820{ }^{\circ} \mathrm{C}$ ). At $t=0$ temperature in the tool is the ambient temperature $T_{0}$.

The temperature field is given by the following equation:

$\mathrm{T}(\mathrm{x}, \mathrm{t})=\left(\mathrm{T}_{\mathrm{i}}-\mathrm{T}_{0}\right) \cdot \operatorname{erfc}\left(\frac{\mathrm{x}}{2 \sqrt{, \mathrm{at}}}\right)+\mathrm{T}_{0}$

with: $a=6.97 .10^{-6} \mathrm{~m}^{2} \mathrm{~s}^{-1}$ the thermal diffusivity.

The variation of temperature versus the distance from the tool-chip interface (cf. Fig. 10) allows us to deter-

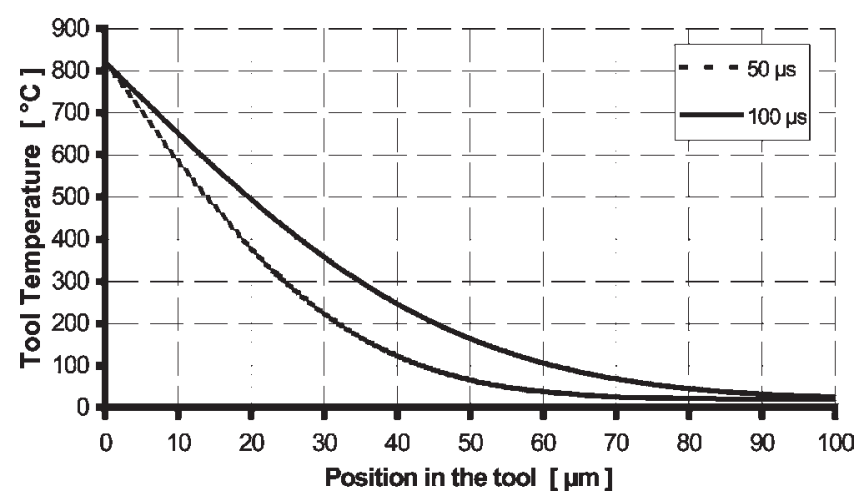

Fig. 10. Temperature profile in the tool. 
mine the tool area for which the temperature is higher than $650{ }^{\circ} \mathrm{C}$. (This temperature corresponds to the lower temperature which can be detected by the camera). For a delay of $50 \mu$ s respectively $100 \mu$ s, the size of this area is $7 \mu \mathrm{m}$, respectively $10 \mu \mathrm{m}$.

\section{References}

[1] M.C. Shaw, Metal Cutting Principles, Oxford University Press, London, 1984.

[2] E.M. Trent, Metal Cutting, second ed., Butterworths, London, 1984.

[3] H. Schulz, T. Moriwaki, High speed machining, Ann. CIRP 41 (1992) 637-643.

[4] G. Barrow, A review of experimental and theoretical techniques for assessing cutting temperatures, Ann. CIRP 22 (1973) 203211.

[5] R. Komanduri, Z.B. Hou, A review of the experimental techniques for the measurement of heat and temperature generated in some manufacturing processes and tribology, Tribol. Int 34 (2001) 653-682.

[6] M.B. Da Silva, J. Wallbank, Cutting temperature: prediction and measurement methods-a review, J. Mat. Proc. Tech. 88 (1999) 195-202.

[7] G. Sutter, A. Molinari, L. Faure, J.R. Klepaczko, D. Dudzinski, An experimental study of high speed orthogonal cutting, Trans. ASME, J. Manufact. Sci. Eng 12 (1998) 169-172.

[8] T. Kitagawa, A. Kubo, K. Maekawa, Temperature and wear cutting tools in high-speed machining of Inconel 718 and Ti-6Al6V-2Sn, Wear 202 (1997) 142-148.

[9] T.I. EL-Wardany, E. Mohamed, M.A. Elbestawi, Cutting temperature of ceramic tools in high speed machining of difficult-tocut materials, Int. J. Mach. Tools Manufac 36 (1996) 611-634.

[10] W. Grzesik, Experimental investigation of the cutting temperature when turning with coated indexable inserts, J. Mach. Tools Manufac. 39 (1999) 355-369.

[11] D. O'Sullivan, M. Cotterell, Temperature measurement in single turning point, J. Mater. Proc. Tech. 118 (2001) 301-308.

[12] H. Ay, W.J. Yang, Heat transfer and life of metal cutting tools in turning, Int. J. Heat Mass Trans. 41 (1998) 613-623.

[13] G. Byrne, Thermoelectric signal characteristics and average interfacial temperatures in the machining of metals under geometrically defined conditions, Int. J. Mach. Tools Manufac. 27 (1987) 215.

[14] E. Usui, T. Shirakashi, T. Kitigawa, Analytical prediction of three dimensional cutting process (part 3): cutting temperature and crater wear of carbide tool, Trans. ASME, J. Eng. Ind 100 (1978) 236-243.
[15] B. Alvelid, Cutting temperature thermo-electrical measurements, Ann. CIRP 18 (1970) 547-554.

[16] D.A. Stephenson, Tool-work thermocouple temperature measurements-theory and implementation issues, Trans ASME, J. Eng. Ind. 115 (1993) 432-437.

[17] P. Lezanski, M.C. Shaw, Tool face temperature in high speed milling, Trans. ASME J. Eng. Ind 112 (1990) 132-135.

[18] M.P. Groover, G.E. Kane, A continuing study in the determination of temperatures in metals cutting using remote thermocouple, Trans. ASME J. Eng. Ind (1971) 603-608.

[19] N. Ranc, V. Pina, P. Herve, Optical measurements of phase transition and temperature in adiabatic shear bands in titanium alloys, J. Phys. IV France 10 (Pr9) (2000) 347-352.

[20] F. Schwerd, Uber die Bestimmung des temperaturfades beim Spanablauf, Z. VDI 9 (1933).

[21] J. Lin, S.L. Lee, C.I. Weng, Estimation of cutting temperature in high speed machining, Trans. ASME, J. Eng. Mater. Tech 114 (1992) 289-296.

[22] G. Boothroyd, Photographic techniques for the determination of metal cutting temperatures, Brit. J. Appl. Phys 12 (1961).

[23] H.T. Young, Cutting temperatures to flank wear, Wear 201 (1996) 117-120.

[24] M.B. Da Silva, J. Wallbank, Temperature measurements in machining using infra red sensor, COBEM97, Cong. Brasileiro de Engenharia Mecânica, Bauru SP, Brazil, 1997.

[25] R.C. Dewes, E. Ng, K.S. Chua, P.G. Newton, D.K. Aspinwall, Temperature measurement when high speed machining hardened mould/die steel, J. Mat. Process. Tech 92-93 (1999) 293-301.

[26] P.K. Wright, E.M. Trent, Metallographic methods of determining temperature gradients in cutting tools, J. Iron Steel Inst. 36 (1973) 4-368.

[27] S.H. Yeo, S.H. Ong, Assessment of the thermal effect on chip surfaces, J. Mater. Proc. Tech. 98 (2000) 317-321.

[28] G. Sutter, L. Faure, A. Molinari, A. Delime, D. Dudzinski, Experimental analysis of cutting process and chip formation at high speed machining, J. de Physique 1997 C3-33-C3-38.

[29] B. Piriou, Mise au point sur les facteurs d'émission, Rev. Int. Htes Temp. et Refract 10 (1973) 283-295.

[30] R.V. Dunkle, Thermal radiation characteristics of surface, Theory and fundamental research in heat transfer: Proceedings of the Annual Meeting of American Society of Mechanical Engineers, New York, Nov. 1960, 1963, pp. 1-31.

[31] A. Antoni-Zdziobek, V. Pina, P. Herve, F. Durand, A radiative thermal analysis for phase change determination of strictly controlled refractory alloys, High Temp. Mater. Sci 37 (1997) 97114.

[32] J. Lin, S.L. Lee, C.I. Weng, Estimation of cutting temperature in high speed machining, J. Eng. Mater. Tech., Trans. of ASME July 114 (1992) 289-1296. 